\title{
Does Total Rotation Range of Motion Asymmetry Have an Effect on Shoulder Isometric Muscle Strength in Young Swimmers?
}

\author{
Ferhat Ozturk ${ }^{1}(\mathbb{D})$, Aykut Ozcadirci ${ }^{1}$ (D), Sukru Alpan Cinemre ${ }^{2}$ (D), Gizem Irem Kinikli ${ }^{1}$ (D) \\ ${ }^{1}$ Hacettepe University, Faculty of Physical Therapy and Rehabilitation Ankara, Turkey. \\ ${ }^{2}$ Hacettepe University, Faculty of Sport Sciences, Ankara, Turkey. \\ Correspondence Author: Ferhat Ozturk \\ E-mail: ferhat.ozturk012@gmail.com \\ Received: $25.01 .2020 \quad$ Accepted: 13.10 .2020
}

\begin{abstract}
Objective: The total rotational range of motion (TRROM) difference in right-left side shoulder glenohumeral joint and muscle strength imbalance in the dominant-nondominant side have been reported to be associated with injury in swimmers. The purpose of this study was to investigate the shoulder isometric muscle strength of young swimmers with and without TRROM asymmetry.

Methods: Assessments of passive TRROM were measured with a goniometer. Hand-held dynamometry was used for the shoulder isometric muscle strength measurements in young swimmers. Thirty-two female swimmers (age: $11.1 \pm 1.5$ years; body weight: $39.8 \pm 9.6 \mathrm{~kg}$ ) and $42 \mathrm{male}$ swimmers (age: $10.9 \pm 1.6$ years; body weight $38.1 \pm 8.3 \mathrm{~kg}$ ) were divided into two groups according to TRROM asymmetry in glenohumeral joint.

Results: Isometric strength of shoulder muscles (flexion, extension, external rotation (ER) , internal rotation (IR), Flexion: Extension and External rotation: Internal rotation) were similar between the groups with TRROM asymmetry $(n=30)$ and without TRROM asymmetry ( $n=44)$ in both dominant and non-dominant sides ( $p>0.05)$. Additionally, while external rotation: internal rotation of dominant side was greater in female $(p=0.04)$, other isometric muscle strength and ratio were similar in both gender $(p>0.05)$.

Conclusions: TRROM asymmetry is one of the many factors affecting muscle strength in overhead sports (basketball, volleyball) but it is not effective in these ages range in the swimming.

Keywords: Asymmetry; muscle strength imbalance; overhead athlete; swim
\end{abstract}

\section{INTRODUCTION}

Swimming is one of the sports performed in water that provides physical development in the most perfect way where gravity is almost zero and all muscles work in harmony (1). The swimming sport requires the upper extremity muscle strength to push the body through the water and advanced rapidly. Although swimming provides a symmetrical and balanced development of body muscles, factors such as internal rotation (IR) and external rotation (ER) muscle strength imbalance, shoulder flexibility, total rotational range of motion (TRROM) asymmetry, previous injury history, incorrect technique of swim, and overuse were found to be associated with shoulder pain and injury (2). Shoulder pain is the most common injury (up to $41 \%$ ) in young swimmers, which may result in poor performance and misses of training $(2,3)$.

TRROM asymmetry is described as the difference in the TRROM of the right and left shoulder (IR plus ER) greater than $10^{\circ}(4-6)$. It has been reported in previous studies that the difference in TRROM between the right and left shoulder is related to injury $(7,8)$. Wilk et al. reported that the risk of injury in upper extremity athletes with a shoulder right and left TRROM asymmetry higher than $5^{\circ}$ is 2.5 times greater (9). These asymmetries in ROM were attributed to changes in bone morphology because of participation in sports in athletes in the process of musculoskeletal development in the humeral head and glenoid $(10,11)$. Repeated torsional swimming stroke over the humeral head leads to further retroversion of the humeral head. This retroversion position affects TRROM by increasing ER (12). Similarly, young swimmers use the shoulders approximately 11.000 times in a week in the overhead position during swim stroke (13).

Training involving multiple repetitive overhead activities may cause muscle strength imbalance, which has been associated with shoulder injury and pain (2). Especially when freestyle swimming training is dominant; shoulder makes continuous repetitive movements in the direction of shoulder, IR, adduction and extension (EX) and these muscles are expected to strengthen further. IR and adduction muscle strength have been declared to be increased in studies, but studies on flexion (FL) and EX strength are 
inconsistent $(13,14)$. McLaine et al. reported that the low EX muscle strength may be associated with a shoulder injury (15). A strong selective increase in shoulder muscle groups that produces the strength required to swim can cause muscle imbalances over time (16). In the literature, there are studies examining the profiles of shoulder muscle strength ( $F L, E X, E R, I R$ ) and muscle strength ratios (FL: EX, $E R: I R)$ in the studies investigated in swimmers $(14,17,18)$. However, these muscle strengths and ratios are different and inconsistent. While there are studies reported as ER: IR ratio 2: 3 in master and college-level swimmers, there are studies that report this ratio as $1: 1(14,17,18)$. The current study was to investigate these muscle strengths and ratios in young swimmers.

Studies examining shoulder rotation movements, strength and mobility in swimmers have been conducted in a larger age range. Muscle strength imbalance and TRROM asymmetry in swimmers were examined separately $(14,15)$. Nevertheless, there is no study in the literature on whether or not TRROM asymmetry affects isometric shoulder muscle strength in young swimmers. Therefore, the purpose of current study was to investigate the shoulder isometric muscle strength of young swimmers with and without TRROM asymmetry. The authors hypothesized that shoulder isometric muscle strength is lower with TRROM asymmetry than without TRROM asymmetry in young swimmers.

\section{METHODS}

When starting the research, the $\mathrm{G} *$ Power ( $\mathrm{G} *$ Power Ver. 3.0.10, Franz Faul, Universität Kiel, Germany) program was used to determine the strength of the study and it was deemed appropriate to include at least 74 people with $85 \%$ power ratio. Signed informed consents were obtained from all swimmers and their parents before the data collection and the study was approved by the Hacettepe University Non-Invasive Clinical Research Ethics Committee (GO 19/876).

\section{Participants}

This cross-sectional observational study was designed for young swimmers aged $8-12$ years ( 32 females; 42 males) who had at least six hours of swimming and 2 hours of dry-land training per week without shoulder pain. All of the athletes were level 2 according to the Tanner stage, and none of them were in the pubertal period. All athletes were referred to study by the swimming club's team coaches. An information meeting was organized for coaches, swimmers, and their parents before the assessments. Swimmers who did feel shoulder pain for the last 2 months, history of shoulder and neck surgery or shoulder dislocation were not included in this study. Before the assessments, all participants completed a questionnaire which includes demographic information (hand dominance, swimming experience, etc.).

\subsection{Range of Motion Measurement}

Assessments of passive TRROM were measured with a goniometer (Model 12-1000, Fabrication Enterprises, Inc: White Plains, New York). The two-measurer method with scapular stabilization which among the other $\mathrm{GH}$ rotation measurements to have the best reliability was used (19). For assessments, athletes were positioned supine with the shoulder $90^{\circ}$ abduction with the elbow at $90^{\circ} \mathrm{FL}$ (Figure 1 a, b). While one examiner stabilized scapula with pressure to the anterior aspect, the other examiner rotated internally and externally until end-feel was felt (20). All TRROM measurements were performed after 5 minutes warm-up. Each test was performed three times for consistency by the same therapist on the same day.

\subsection{Muscle Strength Measurement}

Hand-held dynamometry (HHD) (Model-01165, Lafayette Instrument Company, Lafayette IN, USA) was used for the shoulder isometric muscle strength measurements in young swimmers. HHD is a valid and reliable tool for assessing isometric muscle strength of the shoulder in swimmers (21). For every athlete, strength measurements were applied after TRROM assessments and each swimmer included in the study was informed verbally about the technique of the isometric shoulder strength test application before starting the test. Athletes were positioned supine on the table. FL and EX isometric muscle strength were measured at $140^{\circ}$ abduction of shoulder in the scapular plane with the elbow elongate because this position is functionally for swim when hand entry and early pull-through phase (3). For measurements isometric muscle strength of shoulder IR and $E R$ at $90^{\circ}$ abduction of the arm position with the elbow at $90^{\circ} \mathrm{FL}$ was chosen because this position is functionally appropriate to the mid-pull-through and recovery phases of the swim. To ensure correct movement, athletes were asked to be performed submaximal contraction against the hand of examiner before measurements. Muscle strength was measured without manual stabilization of the shoulder because this position has shown excellent intra-rater reliability in supine to the upper extremity or trunk (22). After the shoulder position was completed, the HHD was placed on the anterior and posterior side of the distal (ulnar styloid process) of the forearm. After completing the shoulder movement position determined for the test, athletes were asked to maintain the maximum isometric contraction for 5 seconds. The tests were performed 3 times and the averages were recorded. In addition, 30 seconds of rest was given between each test and tests were performed bilaterally. During the test, the dynamometer was pushed into the patient's arm without movement in the joint to overcome the maximum muscle strength and verbal encouragement was provided during the test (break test) (4). Because there were different sized swimmers in the study, the average maximum contraction strength (Newtons) was standardized based on body weight to compare shoulder muscle strength 
(3). ER: IR and FL: EX ratios were calculated for each swimmer from the standardized values and were reported.

According to many studies conducted in overhead athletes in the literature, and measurement error associated with standard goniometry, a $10^{\circ}$ cut-off value was chosen considering bone morphology (5-7). Swimmers were divided into two groups according to TRROM asymmetry.

\subsection{Statistical Analysis}

SPSS 23.0 software program (IBM SPSS Statistics version 23.0, IBM Corp. Armonk, New York, ABD) was used for the statistical analyses. It was determined whether the variables were normally distributed by Kolmogorov-Smirnov / ShapiroWilks analytical methods and visual methods (histograms and probability plots). Independent samples t-test was used to compare the data (in terms of TRROM asymmetry and gender) groups because all strength variables were distributed normally. Paired samples t-test was used to compare the data (dominant and non-dominant side isometric muscle strength) dependent variables in females and males. The significance level was determined as $p<0.05$.

\section{RESULTS}

Thirty-two female and 42 male swimmers between 9-12 years old (female: $11.1 \pm 1.5$ years and male: $10.9 \pm 1.6$ years; mean body weight $39.8 \pm 9.6 \mathrm{~kg}$ and $38.1 \pm 8.3 \mathrm{~kg}$, respectively) were included in the present study. All swimmers had an average of 6.4 hours (6-9 hours) practice per week. Two swimmers were excluded from the study according to shoulder pain during the tests.

Thirty swimmers of $74(40.5 \%)$ had TRROM $\left(19.3^{\circ} \pm 6.7^{\circ}\right)$ asymmetry in $\mathrm{GH}$ joint. Isometric shoulder muscle strength measures were distributed normally and there was no difference in isometric muscle strength between with TRROM asymmetry $(n=30)$ and without TRROM asymmetry $(n=44)$ groups $(p>0.05)$ (Table 1$)$.

Table 1. Comparison of isometric shoulder muscle strength in swimmers with and without TRROM asymmetry

\begin{tabular}{|l|c|c|c|c|c|c|}
\hline & \multicolumn{3}{|c|}{ Dominant } & & \multicolumn{2}{c|}{ Nondominant } \\
\cline { 2 - 7 } & TRROM asymmetry & $\begin{array}{c}\text { without TRROM } \\
\text { asymmetry }\end{array}$ & $\mathbf{p}$ & TRROM asymmetry & $\begin{array}{c}\text { without TRROM } \\
\text { asymmetry }\end{array}$ & $\mathbf{p}$ \\
FL & $12.66 \pm 3.51$ & $13.23 \pm 3.18$ & 0.471 & $11.42 \pm 3.24$ & $12.36 \pm 2.73$ & 0.182 \\
EX & $11.03 \pm 1.81$ & $11.13 \pm 1.91$ & 0.833 & $9.80 \pm 1.81$ & $10.24 \pm 1.99$ & 0.342 \\
IR & $15.40 \pm 3.04$ & $15.64 \pm 2.99$ & 0.739 & $13.70 \pm 3.44$ & $14.91 \pm 2.80$ & 0.702 \\
ER & $15.28 \pm 2.58$ & $16.50 \pm 3.05$ & 0.077 & $13.39 \pm 2.90$ & $14.27 \pm 3.02$ & 0.213 \\
FL: EX & $1.14 \pm 0.29$ & $1.19 \pm 0.25$ & 0.537 & $1.17 \pm 0.29$ & $1.22 \pm 0.26$ & 0.409 \\
ER: IR & $0.99 \pm 0.12$ & $1.07 \pm 0.18$ & 0.102 & $0.97 \pm 0.20$ & $0.96 \pm 0.15$ & 0.352 \\
\hline
\end{tabular}

$F L$, flexion; EX, extension; IR, internal rotation; ER, external rotation; TRROM, total rotational range of motion.

There were a similar muscle strengths between dominant and non-dominant sides in both genders $(p>0.05)$. ER: IR ratio significantly higher in females than males $(p<0.05)$. Unilateral shoulder muscle strengths were stronger in the dominant side than non-dominant side in both gender $(p<0.001)$. Unilateral muscle strength (ER: IR, FL: EX) ratios were similar in both gender $(p>0.05)$ (Table 2$)$.

Table 2. Mean isometric shoulder strength and mean strength ratios for females and males.

\begin{tabular}{|c|c|c|c|c|c|c|}
\hline & \multicolumn{3}{|c|}{ Dominant } & \multicolumn{3}{|c|}{ Nondominant } \\
\hline & Females & Males & $p$ & Females & Males & $p$ \\
\hline $\mathrm{FL}$ & $12.15 \pm 2.82^{\mathrm{abd}}$ & $13.66 \pm 3.53^{\mathrm{abd}}$ & 0.052 & $11.45 \pm 2.23^{\mathrm{abd}}$ & $12.38 \pm 3.39^{\mathrm{abd}}$ & 0.183 \\
\hline EX & $10.97 \pm 1.89^{\mathrm{abd}}$ & $11.18 \pm 1.85^{\text {abd }}$ & 0.634 & $10.01 \pm 1.89^{\mathrm{abd}}$ & $10.01 \pm 1.96^{\mathrm{abd}}$ & 0.830 \\
\hline IR & $14.79 \pm 2.69^{\mathrm{acd}}$ & $16.12 \pm 3.11^{\text {acd }}$ & 0.059 & $13.95 \pm 2.74^{\text {acd }}$ & $14.78 \pm 3.35^{\text {acd }}$ & 0.258 \\
\hline ER & $16.25 \pm 3.17^{\text {acd }}$ & $15.81 \pm 2.73^{\text {acd }}$ & 0.526 & $13.66 \pm 2.69^{\text {acd }}$ & $14.11 \pm 3.21^{\mathrm{acd}}$ & 0.524 \\
\hline FL: EX & $1.11 \pm 0.20$ & $1.23 \pm 0.30$ & 0.054 & $1.16 \pm 0.20$ & $1.23 \pm 0.31$ & 0.224 \\
\hline$E R: I R$ & $1.10 \pm 0.16$ & $0.99 \pm 0.15$ & $0.004 *$ & $0.99 \pm 0.18$ & $0.96 \pm 0.17$ & 0.486 \\
\hline
\end{tabular}

${ }^{*}, p<0.05$; significant difference between: ${ }^{a}$, males or females for each test $p<0.001 ;{ }^{b}$, flexion or extension strength $p<0.001 ;{ }^{c}$, internal or external rotation strength $p<0.001{ }^{d}$, dominant and non-dominant sides $p<0.05$. 


\section{DISCUSSION}

This is the first study to compare isometric shoulder muscle strength according to TRROM asymmetry in young swimmers aged between 8-12 years old. The main result of the current study indicated that TRROM asymmetry was not effective on shoulder isometric muscle strength in young swimmers. Additionally, there was no significant relationship between TRROM asymmetry $\left(>10^{\circ}\right)$ in the $\mathrm{GH}$ joint and shoulder mobility.

Asymmetry in TRROM of the GH joint in dominant upper extremity in comparison to non-dominant upper extremity has been associated to shoulder injury in overhead athletes $(7,8)$. In addition, Wilk et al. (9) stated that $5^{\circ}$ TRROM asymmetry leads to a 2.5 times greater possibility of upper extremity injury. Furthermore, Ellenbecker et al. (5) found that the right-left shoulder TRROM asymmetry in junior tennis athletes were $7-9^{\circ}$, also reported that (4) a $5^{\circ}$ TRROM difference in high school and professional baseball athletes. Reeser et al. (23) reported that the right-left shoulder ROM asymmetry in volleyball players was $11^{\circ}$. In addition, $5^{0}$ asymmetry in overhead athletes is recommended to be accepted as pathological (6). Sprague et al. (24) accepted a $10^{\circ}$ threshold asymmetry for athletes performing overhead activity (baseball, swimming, volleyball) to allow for degree of measurement errors. Therefore, in the present study, $10^{\circ}$ TRROM asymmetry in GH joint was considered as a cut-off value in accordance with significant differences in previous studies. Due to young swimmers were participated in this study, we considered the amount of rotation associated with bone morphological changes in the overhead athlete, unlike other studies.

Upper extremity muscle strength is one of the most important factors to be successful in swimming. However, repetitive stresses or other factors may cause an imbalance in shoulder muscle strength. It was stated that the reason for this imbalance may be caused by ROM differences in the $\mathrm{GH}$ joint $(25,26)$. The current study showed that there was no statistically significant difference in all isometric shoulder muscle strength between groups with and without TRROM asymmetry. This means that TRROM asymmetry has no effect on shoulder muscle strength in young swimmers. Although swimming sport is an overhead activity, continuous repetitive movement patterns are performed bilaterally, unlike other sports (volleyball, basketball) might be the main reason for this result. On the other hand, Güney et al. (26) reported that shoulder IR and ER muscle strengths were lower in volleyball and basketball athletes with TRROM asymmetry than athletes without TRROM asymmetry. The authors also stated that the increase in range of motion of the $E R$, which is specific to the sports performed may reveal this result.

Although it is discussed in the literature whether ER:IR ratio is the most suitable measurement technique for shoulder stability in overhead athletes, in previous studies, ER: IR ratio was shown as a risk factor for a shoulder injury in athletes performing an overhead activity $(3,13)$. In addition, the ER: IR ratio $>0.66$ suggests the possibility of injury in overhead athletes (27). Furthermore, the ER: IR muscle strength ratio of the swimmers at college and masters level was reported to be approximately 2:3 (17). However, Magnusson et al. (28) stated this ratio as 1: 1 for swimmers at college and masters levels. ER: IR ratios were approximately 1:1 in both groups in this study. McLaine et al. (15) reported lower extension muscle strength associated with the injury. IR muscle strength is expected to be greater than antagonists in swimmers (13). Opstoel et al. (18) stated that children between the ages of 9 and 11 did not show any physical characteristics specific to the sport and the most important reason for this was the hours spent on the sport. Ericsson has specified the 10000 hours rule for the sport-specific characteristic (29). The reason for this similarity in the current study is maybe that the swimmers of this age have different style of swimming in each training session and the lack of specialization yet.

Contrary to the literature $(14,28)$, there was no statistically significant difference in isometric shoulder muscle strength between males and females, except for the dominant arm ER: IR ratio. The main reason for this result might be the immaturity of our sample accompanying with no technical specialization.

The results of studies involving higher age groups in the literature have shown that muscle strengths are similar between dominant and non-dominant sides due to the bilateral nature of swimming $(14,17,28)$. In contrast to the literature, shoulder muscle strengths were found to be higher on the dominant side in females and males in our study. This result, which is contrary to the bilateral characteristics of swimming, may be due to the fact that swimmers at this young age cannot perform parameters such as arm stroke and breathing during swimming completely symmetrically yet.

Muscle strength ratios are important to follow muscle imbalance around the joint $(17,30)$. In the present study, the FL: EX ratios were similar in females and males. It is important to assess FL: EX ratio in elevation position as a functional position in swimming and may be useful in monitoring muscle imbalance in this age group. Additionally, our results of IR and ER strength are difficult to compare with other studies on young swimmers because athletes in these studies were not normalized to body weight and were evaluated with different protocols like isokinetic dynamometers $(13,16)$. In the literature, a study in which hand dynamometer was used and calculate muscle strength according to body weight; shoulder muscle strength (FL, EX, ER, IR) was found to be greater in males than females, but strength ratios (FL: EX, ER: IR) were reported to be similar (14). The difference between the current study and McLaine's study is the age difference. His study had more swimming experiences because the age range in the study was $14-20$ years. In studies which included a larger age range (mean 16 years old), in females the ER: IR ratio was 0.91 , the $\mathrm{FL}$ : EX ratio was 0.93 , while males ER: IR ratio was 0.86 , the FL: EX ratio was $0.86(14,16)$. Differently, ratios in the current study are higher than these studies. This 
may be due to the body's adaptation to the training as the age grows and the increase in EX and IR muscle strength.

The primary limitation of current study is that age range (812 years) includes a long period and 4 years is an important growth period for individuals at this age. However, it was important for the result that there was no age difference between the groups.

\section{CONCLUSION}

Shoulder muscle strengths and ratios were similar in both groups separated according to TRROM asymmetry. The strength and ROM evaluations contributed to the clinical data for the evaluation of swimmers. It will also shed light on coaches to consider these shortcomings when designing their training programs. The results of this study are an example of swimmers in these ages (8-12 years old). To avoid asymmetry and injury at older ages (elite, master level), the results of this study may be essential. Therefore, prospective studies are needed to show how TRROM asymmetry affects isometric shoulder muscle strengths ( $F L, E X, I R, E R$ ) and ratios (FL:EX, ER:IR) in older (elite, college, master level) swimmers.

\section{Acknowledgements}

The authors would like to thank all the swimmers and coach Efe Orhan of the ANKA sports club and thank the Hacettepe University for providing equipment assistance for this study.

\section{REFERENCES}

[1] Struyf F, Tate A, Kuppens K, Feijen S, Michener LA. Musculoskeletal dysfunctions associated with swimmers' shoulder. Br J Sports Med. 2017;51(10):775-780.

[2] Bak K, Magnusson SP. Shoulder strength and range of motion in symptomatic and pain-free elite swimmers. Am J Sports Med. 1997;25(4):454-459.

[3] Walker H, Gabbe B, Wajswelner H, Blanch P, Bennell K. Shoulder pain in swimmers: a 12-month prospective cohort study of incidence and risk factors. Phys ther sport. 2012;13(4):243249.

[4] Ellenbecker TS, Roetert EP, Bailie DS, Davies GJ, Brown SW. Glenohumeral joint total rotation range of motion in elite tennis players and baseball pitchers. Med Sci Sports Exerc. 2002;34(12):2052-2056.

[5] Ellenbecker TS, Roetert EP, Piorkowski PA, Schulz DA. Glenohumeral joint internal and external rotation range of motion in elite junior tennis players. J Orthop Sports Phys Ther. 1996;24(6):336-341.

[6] Manske R, Wilk KE, Davies G, Ellenbecker T, Reinold M. Glenohumeral motion deficits: friend or foe? Int J Sports Phys Ther. 2013;8(5):537-553.

[7] Burkhart SS, Morgan CD, Kibler WB. The disabled throwing shoulder: spectrum of pathology Part I: pathoanatomy and biomechanics. Arthroscopy: Arthroscopy. 2003;19(4):404-420.

[8] Meyer CJ, Garrison JC, Conway JE. Baseball players with an ulnar collateral ligament tear display increased nondominant arm humeral torsion compared with healthy baseball players. Am J Sports Med. 2017;45(1):144-149.

[9] Wilk KE, Macrina LC, Fleisig GS, Porterfield R, Simpson CD, Harker P, Nick Paparesta, James R Andrews. Correlation of glenohumeral internal rotation deficit and total rotational motion to shoulder injuries in professional baseball pitchers. Am J Sports Med. 2011;39(2):329-335.

[10] Meister K, Day T, Horodyski M, Kaminski TW, Wasik MP, Tillman $S$. Rotational motion changes in the glenohumeral joint of the adolescent/Little League baseball player. Am J Sports Med. 2005;33(5):693-698.

[11] Osbahr DC, Cannon DL, Speer KP. Retroversion of the humerus in the throwing shoulder of college baseball pitchers. Am J Sports Me.d 2002;30(3):347-353.

[12] Wilk KE, Meister K, Andrews JR. Current concepts in the rehabilitation of the overhead throwing athlete. Am J Sports Med. 2002;30(1):136-151.

[13] Batalha NM, Raimundo AM, Tomas-Carus P, Barbosa TM, Silva AJ. Shoulder rotator cuff balance, strength, and endurance in young swimmers during a competitive season. J. Strength Cond. Res. 2013;27(9):2562-2568.

[14] McLaine SJ, Ginn KA, Fell JW, Bird M-L. Isometric shoulder strength in young swimmers. J Sci Med Sport. 2018;21(1):35-39.

[15] McLaine SJ, Bird M-L, Ginn KA, Hartley T, Fell JW. Shoulder extension strength: a potential risk factor for shoulder pain in young swimmers? J Sci Med Sport. 2019;22(5):516-520.

[16] Ramsi M, Swanik KA, Straub S, Mattacola C. Shoulder-rotator strength of high school swimmers over the course of a competitive season. J Sport Rehabil. 2004;13(1):9-18.

[17] Beach ML, Whitney SL, Dickoff-Hoffman SA. Relationship of shoulder flexibility, strength, and endurance to shoulder pain in competitive swimmers. J Orthop Sports Phys Ther. 1992;16(6):262-268.

[18] Opstoel K, Pion J, Elferink-Gemser M, Hartman E, Willemse B, Philippaerts R, Chris Visscher,Matthieu Lenoir. Anthropometric characteristics, physical fitness and motor coordination of 9 to 11 year old children participating in a wide range of sports. PloS one. 2015;10(5):e0126282.

[19] Wilk KE, Reinold MM, Macrina LC, Porterfield R, Devine KM, Suarez K, James R Andrews. Glenohumeral internal rotation measurements differ depending on stabilization techniques. Sports Health. 2009;1(2):131-1366.

[20] Awan R, Smith J, Boon AJ. Measuring shoulder internal rotation range of motion: a comparison of 3 techniques. Arch Phys Med Rehabil. 2002;83(9):1229-1234.

[21] Coinceicao A, Parraca J, Marinho D, Costa M, Louro H, Silva A, Batalha, N. Assessment of isometric strength of the shoulder rotators in swimmers using a handheld dynamometer: a reliability study. Acta Bioeng Biomech. 2018;20(4):113-119.

[22] McLaine SJ, Ginn KA, Kitic CM, Fell JW, Bird M-L. The reliability of strength tests performed in elevated shoulder positions using a handheld dynamometer. J sport rehabil. 2016;25(2).

[23] Reeser JC, Joy EA, Porucznik CA, Berg RL, Colliver EB, Willick SE. Risk factors for volleyball-related shoulder pain and dysfunction. Pm\&r. 2010;2(1):27-36.

[24] Sprague PA, Mokha GM, Gatens DR, Rodriguez Jr R. The relationship between glenohumeral joint total rotational range of motion and the functional movement screen $^{\mathrm{TM}}$ shoulder mobility test. Int J Sports Phys Ther. 2014;9(5):657-664. 
[25] Clarsen B, Bahr R, Andersson SH, Munk R, Myklebust G. Reduced glenohumeral rotation, external rotation weakness and scapular dyskinesis are risk factors for shoulder injuries among elite male handball players: a prospective cohort study. Br J Sports Med. 2014;48(17):1327-1333.

[26] Guney H, Harput G, Colakoglu F, Baltaci G. The effect of glenohumeral internal-rotation deficit on functional rotatorstrength ratio in adolescent overhead athletes. J sport rehabil. 2016;25(1):52-57.

[27] Ellenbecker TS, Davies GJ. The application of isokinetics in testing and rehabilitation of the shoulder complex. J Ath. Train. 2000;35(3):338-350.
[28] Magnusson SP, Constantini NW, McHugh MP, Gleim GW. Strength profiles and performance in Masters' level swimmers. Am J Sports Med. 1995;23(5):626-631.

[29] Ericsson KA, Krampe RT, Tesch-Römer C. The role of deliberate practice in the acquisition of expert performance. Psychological review. 1993;100(3):363-406.

[30] Byram IR, Bushnell BD, Dugger K, Charron K, Harrell Jr FE, Noonan TJ. Preseason shoulder strength measurements in professional baseball pitchers: identifying players at risk for injury. The Am J Sports Med. 2010;38(7):1375-1382.

How to cite this article: Ozturk F, Ozcadirci A, Cinemre SA, Kinikli GI. Does Total Rotation Range of Motion Asymmetry Have an Effect on Shoulder Isometric Muscle Strength in Young Swimmers?. Clin Exp Health Sci 2020; 10: 389-394. DOI: 10.33808/ clinexphealthsci.679983 